\title{
PANTEIA: UMA IMAGEM VERBAL
}

\author{
Melina RodolPho*
}

Universidade de São Paulo

\begin{abstract}
Resumo. Analisamos aqui a écfrase de personagem, já que esta é aplicada nos textos fisiognomônicos. Procuramos entender o que é a fisiognomonia e como a teoria fisiognomônica contribui para a composição de retratos por meio da análise da écfrase de Filóstrato do livro II, 9 em Imagens, texto em que retrata a aparência de Panteia por meio do ethos já conhecido da personagem. O tratado fisiognomônico adotado como base para a análise do retrato de Panteia é o De Physiognomonia Liber (IV d.C.), de autoria anônima.
\end{abstract}

Palavras-chave. Écfrase; enargia; fisiognomonia; retrato; ethos.

D.O.I. 10.11606/issn.2358-3150.v19i1p110-122

\section{ENARGEIA, EKPHRASIS E FISIOGNOMONIA}

Enargeia é um conceito que frequentemente aparece na teoria retórica antiga, no entanto, sistematizá-la não é tarefa simples. Embora dependa de procedimentos retóricos e poéticos, a construção de uma imagem que na verdade está ausente exige conhecimentos que ultrapassam o âmbito retórico-poético; visto tratar-se de tema amplamente discutido nessa publicação, tal investigação não será o foco em nosso artigo.

Em resumo, podemos dizer que a enargia (enargeia) e a écfrase (ekphrasis) têm em comum o efeito de visualização. A écfrase é essencialmente descritiva - por isso é habitualmente associada à descriptio em latim - e a enargia é um resultado obtido por meio do emprego de diversas figuras retóricas.

Adotando-se o mecanismo da descrição detalhada, é possível produzir um quadro que quase se apresenta aos olhos. De acordo com Hélio Teão (I d.C.), autor de progymnásmata no período da Segunda Sofística, há vários tipos de écfrase tais como de personagens, ações, lugares, épocas e

\footnotetext{
* Doutora em Letras Clássicas pela Universidade de São Paulo (2014). O conteúdo deste artigo é uma adaptação da apresentação em inglês no "IV Colóquio Internacional Visões da Antiguidade - Luzes sobre Enargeia e Evidentia" (2013), cuja comunicação foi dividida em duas partes: a primeira de Rosangela S. S. Amato que discorreu acerca da enargia e da écfrase no quadro de Panteia, a segunda, proferida por mim, acerca dos aspectos fisiognomônicos no mesmo texto, com o título único "Pantheia, a verbal picture: Enargeia, Ekphrasis and Physiognomony".

"*Artigo recebido em 05.set.2016 e aceito para publicação em 25.out.2016.
} 
modos - afirmação que pode ser corroborada pela variedade de exemplos da tradição poética.

Interessa-nos, neste momento, a écfrase de personagens (prosopa) já que analisaremos como a écfrase é aplicada nos textos fisiognomônicos e também sua contribuição para produzir enargia. Procuraremos estabelecer a contribuição da fisiognomonia na composição de retratos analisando a écfrase de Filóstrato do livro 2.9 em Imagens, texto em que ele procura pintar a aparência de Panteia por meio do ethos já conhecido da personagem.

Em primeiro lugar, analisemos o conceito de fisiognomonia (Фvбı$\gamma \nu \omega \mu$ ovia) que significa, de acordo com A Greek-English Lexicon, ${ }^{1}$ a ciência ou arte de julgar um homem por suas características físicas; segundo André Lalande, ${ }^{2}$ trata-se da "ciência da relação entre o caráter e o aspecto físico dos indivíduos e especialmente entre o caráter e os traços do rosto. Arte de adivinhar o caráter a partir desses signos exteriores". Constatamos que a fisiognomonia é, portanto, definida como ciência e arte, o que nos leva a questões tradicionais como a definição de episteme e techne na teoria antiga, principalmente se considerarmos sua conexão com a medicina.

Não há tratados antigos que discutam propriamente o que seja a fisiognomonia, mesmo os tratados fisiognomônicos não são esclarecedores em sua definição, há, no entanto, consenso quanto à fisiognomonia enquadrar-se na área da medicina em razão de alguns pontos de similaridade dos métodos, tais como a busca por explicação nas condições climáticas e na influência dos humores sobre o temperamento das pessoas.

Os gregos no período arcaico relacionavam as doenças à ação dos deuses e ao universo, mas a partir do século vi a.C. observa-se um novo pensamento, filosófico-naturalista, ${ }^{3}$ com o aparecimento dos filósofos-médicos que, posteriormente, criaram as escolas médicas e produziram os textos que hoje fazem parte do corpus hipocrático, a partir destes, portanto, começase a assumir valores racionais associados à medicina. $\mathrm{O}$ corpus hipocrático trata a medicina como techne, ou ars em latim; nesses escritos, a medicina é mencionada como uma techne subestimada e considerada inferior:

1. A medicina é a mais notável de todas as artes [ $\tau \varepsilon \chi v \varepsilon ́ \omega v]$, mas no momento, por ignorância dos que a praticam e daqueles que julgam tais pessoas de forma irrefletida, está em posição muito inferior a todas as demais artes [ $\tau \tilde{\omega} v \tau \tau \varepsilon \chi v \varepsilon \dot{\varepsilon} \omega v]{ }^{4}$

\footnotetext{
${ }^{1}$ Compilação de Liddell and Scott 1996.

${ }^{2}$ Lalande 1999.

${ }^{3}$ Cf. Barbosa e Lemos 2007, 117.

${ }^{4}$ Hp. Lex, 1. Trad. Wilson. A. Ribeiro Junior. In: Cairus; Ribeiro 2005.
} 
Techne é usualmente relacionada à arte e episteme à ciência, embora esta definição não seja tão exata se observarmos, por exemplo, a teoria platônica ou peripatética. No diálogo platônico Charmides, 165c, a medicina aparece como episteme, cujo resultado é a saúde, entretanto, a medicina é também mencionada entre as quatro technai em Górgias (464b). ${ }^{5}$ Dentre as acepções de غ̇ंı cimento científico, ciência", ${ }^{6}$ contemplando igualmente a noção de techne.

Dentre os antigos tratados de fisiognomonia, um é atribuído a Aristóteles (III a.C.), mas foi elaborado provavelmente por escritores sob a influência da escola peripatética, cujo texto foi preservado e há algumas edições nos dias atuais. Há uma obra do médico Loxo, do mesmo século, cuja fonte é o tratado anônimo De Physiognomonia Liber (Iv d.C.), o qual cita, além de Loxo, o tratado pseudoaristotélico e outro de Polemão (II d.C). A obra de Polemão, escrita em grego, teve grande influência no mundo árabe, onde foi traduzida para o árabe e por meio dessa versão foi amplamente divulgada. Há ainda o tratado de Adamantio (Iv d.C.), que é uma paráfrase em grego do tratado de Polemão.

Alguns tratados fisiognomônicos trazem em sua introdução alguns elementos que nos auxiliam nessa investigação do que seja a fisiognomonia. Em Physiognomonica de Adamantio, o Sofista, o autor menciona Aristóteles numa clara menção à conhecida obra pseudoaristotélica; Polemão, por sua vez, reconhece a existência de outros estudiosos do assunto.

Adamantio chama a fisiognomonia de $\mu \varepsilon \theta$ oঠov - cuja acepção remete em geral à ideia de uma prática regulada por um sistema ${ }^{7}$ - e propõe como objetivo de sua obra parafrasear Polemão, acrescentando à disciplina

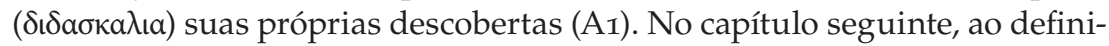
-la, o autor atribui a tarefa de praticar a fisiognomonia aos homens divinos, pois apenas esses podem reconhecer todos os sinais do caráter, não somente os típicos de cada povo, facilmente reconhecíveis, como também os particulares de cada indivíduo; entretanto, segundo o autor, mesmo homens sensíveis deveriam estudar tal arte com entusiasmo, utilizando aqui o termo $\tau \dot{x} \chi v \eta$, e o texto segue orientando os que desejam estudá-la. No terceiro ca-

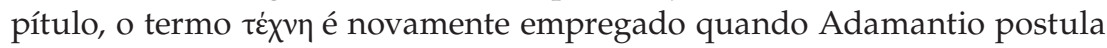
acerca da combinação de sinais, importante para a prática fisiognomônica.

O Anônimo não discute amplamente a definição de fisiognomonia, mas logo na introdução a apresenta como institutio, cuja acepção ${ }^{8}$ com-

${ }^{5}$ Stanford Encyclopedia of Philosophy. "Episteme and Techne".

${ }^{6}$ Cf. Lalande 1999.

${ }^{7}$ Cf. Lalande 1999.

${ }^{8}$ Saraiva 2000. 
preende "ciência, método". Na conclusão desse tratado, capítulo 133, o autor afirma ser doctrina, que significa "ciência" e também "arte".

Considerando-se esse breve histórico da fisiognomonia aqui esboçado, podemos afirmar que era um sistema regulado por uma teoria comum, como pode ser constatado a partir da leitura dos mais tradicionais tratados da Antiguidade acerca do assunto; entretanto, também se associava à adivinhação e, nesse caso, seu estatuto como ciência estaria comprometido na cultura clássica. Baroja ${ }^{9}$ afirma que a fisiognomonia teria se corrompido na Idade Média porque os critérios de sua teoria tornaram-se mais problemáticos quando unidos à arte de adivinhação, colocando-os em dúvida. Neste período, as práticas divinatórias eram tidas como pagãs pelo Cristianismo, tornando-as questionáveis.

Os tratados fisiognomônicos descrevem partes do corpo e de acordo com sua aparência há um ethos específico. São três métodos principais: o método zoológico estabelece paralelo entre os animais e os homens, tanto no aspecto físico, como também com relação às características de temperamento; o etnológico examina as características a partir dos grupos étnicos; o anatômico concentra-se na observação dos elementos físicos, incluindo até mesmo aspectos resultantes da manifestação das emoções.

Não há muita literatura a respeito da circulação dos tratados fisiognomônicos, mas é possível conjecturar que a teoria estava bastante presente na cultura antiga. Elisabeth Evans ${ }^{10}$ é cuidadosa quando analisa algumas obras de escritores clássicos sob a perspectiva fisiognomônica, afirmando que existia uma "consciência fisiognomônica".

Aubert, ${ }^{11}$ em estudo acerca do método zoológico, fala a respeito do histórico da prática fisiognomônica na Antiguidade e explica que embora a fisiognomonia tenha surgido no Oriente, os primeiros a fazer uma sistematização escrita do que era já utilizado, mas não teorizado, foram os ocidentais. Mais adiante em seu artigo, Aubert atribui às escolas peripatética e estoica o interesse na fisiognomonia durante o período helenístico, mas apenas nos séculos II e IV da nossa era teve grande popularidade; entretanto, podemos identificar o emprego da fisiognomonia na poesia e na prosa em caracterizações físicas ${ }^{12}$ desde Homero.

\footnotetext{
${ }^{9}$ Cf. Baroja 1988, 41-2.

${ }^{10}$ Evans 1969.

${ }^{11}$ Cf. Aubert 2004, 9.

${ }^{12}$ Cf. Aubert 2004, 14 e 34.
} 


\section{RETRATO DE PANTEIA}

Retornemos ao nosso objeto de estudo e analisemos a pintura de Panteia levando em consideração a existência da consciência fisiognomônica. Procuraremos estabelecer a relação com a teoria da fisiognomonia uma vez que a obra de Filóstrato data de período posterior aos tradicionais tratados.

Panteia, uma personagem conhecida na obra Ciropédia de Xenofonte (v-IV a.C.), onde não nos é apresentada uma descrição física, é descrita por Filóstrato, o Velho (II-III d.C.) de acordo com seu ethos. Filóstrato produz uma imagem que apenas a habilidade do pintor parece ser capaz de expressar, a beleza de Panteia é visível através do ethos porque ele reconhece e vê os traços físicos nos sinais de sua alma. Na verdade, os fisiognomonistas fazem o oposto em seus tratados.

Xenofonte, em Memorabilia 3.10, afirma por meio da personagem Sócrates, durante uma discussão se é ou não possível reproduzir o ethos, que o rosto expressa estados da alma e características morais.

4. [Sócrates]

- Sim, mas, quando observamos o seu rosto, não vemos no homem expressões de amor e de ódio?

- Sim, parece-me que sim.

- E não é possível imitar esses sentimentos na expressão do olhar?

- Sem dúvida.

- E parece-te que têm igual expressão os rostos dos que experimentam as alegrias e as tristezas dos seus amigos e daqueles que não as sentem?

- Claro que não, por Zeus, nas alegrias mostram-se radiantes e nas tristezas tonam-se sombrios.

- Ah! E essas expressões também podem ser pintadas, não podem?

- E muito bem.

- Então, também a arrogância e a independência, a humildade e o servilismo, a sensação e a ponderação, a insolência e a rudeza que são visíveis na postura dos homens, quer estejam parados quer estejam em movimento. ${ }^{13}$

Os tratados fisiognomônicos são irregulares, alguns traços são ensinados como símbolos de determinados aspectos de personalidade, mas seus significados podem mudar quando combinados a outros sinais; os escritores de tais tratados dizem que são capazes de fazer esta análise diferenciada, reunindo todos os sinais, como afirma Adamantio (A2) e o Anônimo quando introduz a longa descrição dos olhos:

\footnotetext{
${ }^{13}$ Xen. Mem. 3.10. Trad. Ana E. Pinheiro.
} 
20. Agora é preciso discutir a respeito dos olhos, onde a essência de toda a fisiognomonia está estabelecida. Com efeito, se os olhos tiverem reafirmado os sinais de outras partes, então tais sinais são mais seguros e confiáveis. [...] Em suma, os indícios dos quais já falamos e dos quais ainda trataremos devem ser justapostos e acrescentados aos indícios dos olhos, de modo que, se não forem contraditos, tampouco tomados como ambíguos, mas antes confirmados pelos olhos, são então seguros. ${ }^{14}$

O retrato de Panteia apresenta algumas ligações com a teoria fisiognomônica já que Filóstrato a "pinta" com sinais do ethos apresentado antes por Xenofonte, relação que claramente permeia a análise fisiognomônica:

O punhal já cravado no peito, mas com tal determinação que nem mesmo um gemido lhe escapa com o golpe. Ela jaz, a boca mantendo seu desenho perfeito e, por Zeus, a graça, cujo brilho em seus lábios, mesmo silentes, se revela. Ainda não soltou o punhal, e o empurra ainda caindo sobre o cabo: o cabo se assemelha a um tronco dourado com ramos em esmeralda, mas ainda mais belos são seus dedos!

Não se alterou em nada sua beleza com a dor, nem ela parece sofrer, mas partir radiante, pois a si própria envia. E não parte como a esposa de Protesilau, com as guirlandas dos ritos báquicos, nem como a de Capaneu, ataviada como para um sacrifício, mas com sua beleza sem adornos, como se mostrava a Abradates e assim a conserva e leva, os cabelos negros soltos e espessos derramados sobre as espáduas e a nuca, deixando entrever apenas o branco colo, que ela arranhou, sem enfear, porém. As marcas das unhas são mais encantadoras que uma pintura.

O rubor em suas faces, nem mesmo depois de morta desapareceu, a graça e o pudor o sustêm. Olhe as narinas, levemente abertas, formando a base para o nariz de onde, como dois ramos em crescente, surgem as sobrancelhas negras, sob a fronte branca. E os olhos, menino, vamos contemplar não o seu tamanho, nem se negros, mas sua inteligência, quanta existe neles e, por Zeus, quanto da nobreza da alma sorveram. Despertando piedade, não deixaram de mostrar seu brilho jubilante e são corajosos, mais por resolução do que por temeridade. E, apesar de sabedores da morte, ainda não partiram. Companheiro do amor, o desejo sobeja nos olhos, a tal ponto que visivelmente deles transborda.

Eros está pintado na trama das ações, e também a lídia recolhendo o sangue, como você vê, nas pregas de sua veste dourada. ${ }^{15}$

O foco da descrição de Panteia está na cabeça: primeiro, somos apresentados ao denso cabelo negro, solto e não tão curto, porque cai sobre a nuca e os ombros; podemos também ver sua pele alva.

Panteia já está morta na descrição de Filóstrato, mas sua imagem ainda é vívida, não apenas aos "olhos do leitor", mas ela ainda tem algum brilho, como se ela não estivesse morta. A boca dela mantém um formato perfeito, não desfigurado pela morte, e os lábios brilhantes mostram sua

\footnotetext{
${ }^{14}$ De Physiognomonia Liber 20. Tradução nossa.

${ }^{15}$ Philostr. Im. 4-6. Tradução cedida por Rosangela S. S. Amato. A tradução faz parte de pesquisa de Doutorado não concluída: Écfrase e fantasia: Pintura e (m) Palavras, Filóstrato, o velho. Agradeço à autora, que disponibilizou o texto e autorizou a citação.
} 
juventude, embora estejam em silêncio. Os dedos, ainda segurando a adaga, são mais bonitos do que o cabo dourado cheio de esmeraldas. $\mathrm{O}$ tratado pseudoaristotélico Physiognomonica menciona dois tipos de cabelo (8o6b6): finos mostram covardia, se grossos, coragem. Polemão compara as pessoas com cabelo abundantemente grosso ao animal selvagem, mas a falta de cabelo é sinal de deslealdade e maldade, portanto, o ideal é o meio-termo; ele ainda menciona que o cabelo ondulado indica covardia e cupidez $(B, 37$, 39a). Polemão atribui os cabelos finos às mulheres e aos homens o aspecto contrário $(B, 2,24 a-25 a)$.

A cor preta dos cabelos não é um bom sinal para o Anônimo, pois ele caracteriza como um sinal feminino a coloração escura (cap. 6); entretanto, ao analisar as variedades de cabelo (cap. 14), o Anônimo considera o cabelo um pouco escuro como sinal de bom caráter, se forem finos, o que também ocorre com outras tonalidades, o sinal distintivo parece então ser a espessura, visto que as mesmas cores em cabelos espessos indicam disposições éticas no âmbito da ferocidade. Sabemos que o ethos masculino na teoria fisiognomônica é sempre considerado melhor que o feminino, portanto, o cabelo grosso é em geral um sinal positivo, já que costuma ser atribuído ao homem, como observam Polemão (B, 37, 39a) e o Anônimo:

5. Vamos para as características do corpo masculino. A cabeça grande e o cabelo mais espesso, ruivo ou preto avermelhado, duro, moderadamente anelado [...].

90. Vamos constituir o homem forte. Deve ser um homem de corpo reto, os flancos, as articulações, as extremidades dos pés e das mãos são firmes, os ossos grandes, o cabelo bem grosso, o ventre largo, um tanto côncavo, os ombros fortes, as escápulas separadas, o peito e as costas firmes $[\ldots] \cdot{ }^{16}$

Em geral, a vermelhidão da face pode indicar várias disposições anímicas: alguns escritores adotam a coloração vermelha para mostrar algum pathos específico como raiva, vergonha, insanidade ou paixão. Na écfrase de Panteia seu uso é um recurso para mostrar como ela parece vívida mesmo em sua morte. Na teoria fisiognomônica, o sangue é usualmente associado a um ethos furioso, tal como descreve o Anônimo (cap. 79) a respeito da pessoa de olhar sangrento e veias patentes no pescoço e têmporas, este quadro representa uma pessoa irada, violenta e insana; o vermelho muito intenso (ignitus) é sinal de insanidade; o enrubescimento do rosto é tanto sinônimo de pudicícia como de vinolência.

As características extremas jamais são consideradas boas pelos fisiognomonistas, podemos então afirmar que a cor branca da pele de Panteia com

${ }^{16}$ De Physiognomonia Liber, 5; 90. Tradução nossa.

Let. Cláss., São Paulo, v. 19, n. 1, p.110-122, 2015 
a vermelhidão de sua face é também um sinal virtuoso, uma vez que a tez branco-avermelhada é típica dos indivíduos fortes e animosos (Anônimo, cap. 79), mas apenas a cor branca é típica de mulher (Anônimo, cap. 6) - os sinais femininos são mostrados de maneira negativa se comparados aos masculinos na fisiognomonia. O tratado pseudoaristotélico declara que, entre outros sinais, semblante pálido e cabelos finos pertencem ao covarde (807b5-6). Polemão descreve os gregos como um povo sem miscigenação, de cor branca misturada ao vermelho (37b/ B32) - essa vermelhidão da face e do corpo é sinal de astúcia para Polemão. Por outro lado, Polemão julga uma pessoa com o rosto avermelhado como alguém desejoso, perseverante e traidor (35a).

O rosto de Panteia, portanto, corrobora um ethos corajoso, refletido em suas ações, estas conhecidas provavelmente a partir da Ciropédia, em que é fiel ao marido e não teme a morte.

Quintiliano, na Institutio Oratoria 11.3.78, diz que o sangue é muito expressivo na actio porque pode indicar vergonha ou pusilanimidade e o ideal é o equilíbrio entre a vermelhidão e a palidez:

[...] o sangue que se move conforme o estado mental: na vergonha, atinge a pele tênue, a qual é tomada de rubor; no medo, refugia-se e some todo, causando gélida palidez. Equilibrada a mente, produz uma espécie de serena neutralidade. ${ }^{17}$

Filóstrato diz que Panteia é naturalmente bonita, sem adornos, destacando-se não só sua beleza física, mas um ethos igualmente belo. Seu nariz é delicado, com narinas levemente abertas; aqui Filóstrato adota uma metáfora para tornar visível a imagem descrita: o nariz é a estrutura para dois ramos crescentes, em outras palavras, as sobrancelhas. O ethos virtuoso de Panteia é constantemente representado por uma aparência harmoniosa, onde as sobrancelhas e o nariz estão graciosamente unidos.

O nariz muito estreito, redondo e fechado manifesta estultícia em $D e$ Physiognomonia Liber; ao passo que o nariz bem aberto manifesta vivacidade e força (cap. 51). Logo, uma vez que o equilíbrio fornece os sinais ideais e há, nesse manual fisiognomônico, exemplos de animais com nariz mais aberto ou largo representando, ao mesmo tempo, qualidades e defeitos, como o cavalo (cap. 118) e o boi (cap. 120), podemos concluir que Panteia tem o nariz perfeito para indicar uma pessoa virtuosa pela perspectiva fisiognomônica, de narinas levemente abertas.

${ }^{17}$ Quint. Inst. Or. 11.3.78. Tradução cedida por Maria Fernanda D. de Aguiar. Agradeço à tradutora, bacharel em Latim, pela colaboração nesse excerto e também pela autorização para publicar sua tradução neste artigo. Texto em latim: [...] sanguis ille qui mentis habitu movetur et, cum infirmam verecundia cutem accipit, effunditur in ruborem, cum metu refugit, abit omnis et pallore frigescit; temperatus medium quoddam serenum efficit. 
O objeto da descrição de Filóstrato é o rosto, cujo foco está nos olhos. A forma como Filóstrato descreve aqui não é clara a respeito das características dos olhos, podemos pensar que eram provavelmente grandes

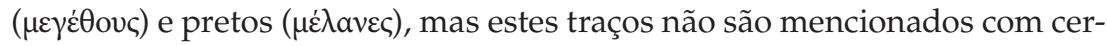
teza; o que realmente sabemos é que são olhos brilhantes ( $\varphi$ aı $\rho \tilde{\omega} \varsigma$ ) e ainda podemos ver neles algumas características do ethos, pois transparecem sua inteligência, coragem e nobreza.

De acordo com os fisiognomonistas, a essência da fisiognomonia reside nos olhos porque eles são portas da alma (Anônimo, cap. 10), além de serem considerados os melhores sinais; entretanto, é preciso analisar os sinais de todo o corpo junto aos olhos. Tais afirmações mostram a importância da aparência dos olhos para a teoria fisiognomônica, uma vez que todos os sinais devem ser confirmados por eles.

Uma grande parte dos tratados de Polemão e do Anônimo dedica-se ao estudo dos olhos. No retrato de Panteia, o escritor dá aos olhos atenção especial, solicitando ao "espectador/ leitor" que contemple os olhos da retratada:

E os olhos, menino, vamos contemplar não o seu tamanho, nem se negros, mas sua inteligência, quanta existe neles e, por Zeus, quanto da nobreza da alma sorveram. Despertando piedade, não deixaram de mostrar seu brilho jubilante e são corajosos [...].

O tratado pseudoaristotélico traz como coloração escura dos olhos o

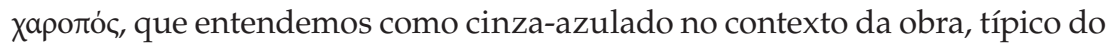
homem corajoso (807b1) e do ethos leonino (8ogbig); no Anônimo, esta cor é própria do ânimo masculino (cap. 5).

Polemão diz que os olhos brilhantes e luminosos são sinal de uma pessoa boa (A, 5). O Anônimo, no capítulo 21, escreve: "Os olhos que brilham como gotículas de um líquido resplandecente indicam um caráter muito suave e muito agradável". No capítulo 34, ao falar de olhos escurecidos, o Anônimo cita Polemão ao dizer que os melhores olhos são "cinza-azulados, úmidos, penetrantes, grandes, cheios de luz".

É muito difícil estabelecer qual cor seja, de fato, um sinal bom ou ruim, porque há muitos elementos relacionados. Geralmente, em todos os tratados, o ethos correspondente a olhos escuros não é bom (Anônimo, caps. 27 e 28), pois quando verdadeiramente pretos representam a fraqueza e a covardia; no entanto, há sempre um tipo como exceção, no pseudoaristotélico, por exemplo, os olhos que não chegam a ser pretos, mas de tonalidade acastanhada ( $\xi_{\alpha} \theta$ óc) indicam os corajosos, os olhos claros e manchados, as pessoas covardes - o autor explica que a característica relativa às manchas ocorre quando as pessoas estão com medo, pois os olhos empalidecem, mas ficam com manchas coloridas (812b1-12). 
Os olhos de Panteia movem o espectador na cena de sua morte, entretanto, eles ainda brilham e mostram coragem, cuja ação não parece influenciada por algum vício, tal como a imprudência; seu ethos é amoroso, mas também leal e corajoso, o suicídio é condizente com o caráter de Panteia sob esta perspectiva. Os olhos proeminentes reunidos a elementos da figuração de Panteia revelam o caráter justo e amoroso sob a perspectiva fisiognomônica como se observa no Anônimo:

32. [...] Uma única espécie de olhos proeminentes é boa: se forem grandes, brilhantes, bem claros e úmidos, indicam o justo, dócil, cauteloso e amoroso. [... $]^{18}$

Mais uma vez, apesar de sua morte, a aparência de Panteia parece vívida porque seus olhos ainda estão vivos, mesmo o desejo, parceiro do amor, ainda transborda deles - esta vividez já fora sugerida antes, mas os olhos contribuem para destacá-la ainda mais.

Refletindo a respeito da écfrase e da enargia, entendemos a primazia da visão sobre os demais sentidos porque o propósito de tais procedimentos é fazer visível algo que, na verdade, está ausente; desta maneira, é possível deleitar, ensinar e comover de modo mais eficiente. A fisiognomonia procura, por sua vez, tornar inteligível o caráter, que é invisível aos olhos, por meio da observação dos sinais físicos. O recurso da écfrase no retrato de Panteia contribui para sua elaboração na medida em que se constrói uma imagem física simultaneamente ao ethos. O olhar de Panteia é extremamente significativo neste complexo contexto em que Filóstrato nos faz crer que de fato vemos o quadro (provavelmente imaginário) com olhos incorpóreos, cuja vitalidade da personagem reside sobretudo nos olhos, pelos quais acreditamos ver além do que o quadro propõe, revelando-nos suas qualidades morais.

Antes no texto, Filóstrato já afirmara que mesmo a dor não levou a beleza de Panteia, outra informação que fortalece sua imagem harmoniosa; a écfrase aqui poderia expressar dor e desespero por meio das reações exageradas do corpo, ${ }^{19}$ porém, temos uma imagem serena.

Xenofonte, por sua vez, descreve Panteia na Ciropédia destacando somente suas virtudes e acerca da aparência há apenas menção à grande beleza. No livro 5, Araspas - que é responsável pela proteção de Panteia - fala a respeito dela para Ciro: ela está sentada entre suas criadas e vestida como elas, indício de modéstia e humildade, sendo então identificada por seu véu

${ }^{18}$ De Physiognomonia Liber, 32. Tradução nossa.

${ }_{19}$ Cf. Rodolpho 2012, 212-21, em análise da écfrase do episódio de Laocoonte na Eneida 2.199-224. 
porque as roupas eram simples e ela olhava fixamente o chão. Quando ela se levanta, temos uma breve enumeração de alguns aspectos que chamam atenção e a diferenciam de outras mulheres na cena: estatura, força, honestidade e beleza. Ela chorava copiosamente a ausência do marido, que estava na guerra, a ponto de umedecer sua vestimenta. Durante esta cena, ela tirou o véu e Araspas pôde ver seu rosto, pescoço e mãos e, a partir desta visão, ele considerou que ninguém jamais vira uma mulher tão bonita em toda a Ásia.

No livro 6, Araspas está completamente apaixonado por Panteia, mas ela se manteve leal ao marido, relatando isso a Ciro apenas após ser ameaçada com violência. Abradates, seu marido, retorna e ela ainda o ajuda com os preparativos de sua nova partida à guerra, em que ele luta por Ciro. No fim, quando Abradates morre, ela comete suicídio para ficar com ele, trata-se do evento que vemos pintado no quadro de Filóstrato.

Abradates é representado por Filóstrato de modo que seu ethos não é figurado, visualizamos uma imagem triste: há sangue sobre ele, manchando o corpo cheio de feridas e sua vestimenta, a armadura feita com ornamentos de Panteia, segundo informação observada no livro 6 da $\mathrm{Ci}$ ropédia. Há apenas um aspecto sobre a aparência de Abradates: uma barba rala, destacando sua juventude, aspecto que aparece brevemente do De Physiognomonia Liber do Anônimo:

84. [...] são animosos aqueles cujas faces, depois do começo da juventude, são de certo modo mais duras e imberbes, porém, na extremidade do queixo é coberta por barba. ${ }^{20}$

Podemos dizer que seu ethos também é pintado se considerarmos o conhecimento da obra de Xenofonte, mas mesmo sem esse conhecimento prévio, a impressão transmitida ao leitor é de que Abradates é um homem corajoso e virtuoso, porque ele é digno do amor da virtuosa Panteia.

É impossível para um pintor mostrar todos os elementos desta história. Se a pintura realmente existiu, o artista representou o momento que resume não apenas a história, mas, acima de tudo, o ethos de Panteia, o que a conduziu ao suicídio. Tratando-se de uma imagem verbal - não importa se a pintura é real ou imaginária -, Filóstrato é também limitado a este mesmo momento e deve dar todo tipo de informação acerca da imagem para compô-la.

${ }^{20}$ De Physiognomonia Liber, 84. Tradução nossa. 


\section{CONSIDERAÇÕES FINAIS}

Ciência ou arte, a teoria fisiognomônica se apresenta em alguns momentos de forma superficial e seus preceitos não foram bem sistematizados, porém, a consciência fisiognomônica já estava presente nos mais diversos gêneros.

Ao retomarmos o conceito da écfrase, é inevitável associar a imagem de Panteia à categoria de prosopa, ou prosopografia, que consiste na descrição de personagens cujos exemplos dos progymnásmata são apenas de descrições físicas. O que essa écfrase de Filóstrato faz é descrever o ethos, construindo uma etopeia, uma modalidade descritiva presente na teoria retórica; a écfrase de Panteia é uma combinação de descrição moral e física numa tentativa de mostrar seu ethos virtuoso em harmonia com sua bela aparência. A enargia aqui opera de duas maneiras: nós vemos a ação de Panteia suicidando-se capturada na pintura e, concomitantemente, seu retrato.

Em De Physiognomonia Liber, o Anônimo, ao introduzir sua obra, ensina ser indispensável observar as características do corpo para entender a alma (cap. 2) porque a alma assume a aparência do corpo assim como o ar toma a forma dos instrumentos de sopro. Podemos inferir, portanto, que Filóstrato descreve a aparência de Panteia, de beleza notável na alma e na face, a partir do seu ethos, estabelecendo assim relação intrínseca entre ambos.

\section{REFERÊNCIAS}

Amato, R. S. S. [sem publicação]. Écfrase e fantasia: Pintura e(m) Palavras, Filóstrato, o velho. Universidade de São Paulo.

André, J. 1981. Anonyme Latin. Traité de Physiognomonie. Paris: Les Belles Lettres.

Aubert, J. J. 2004. La méthode zoologique dans les traités de physiognomonie. Université de Neuchâtel - Faculté des lettres et sciences humaines/ Sciences de l'Antiquité.

Barbosa, D. F. e Lemos, P. C. P. 2007. A medicina na Grécia antiga. Rev Med (São Paulo), 86(2):117-19.

Baroja, J. C. 1988. Historia de la fisiognómica. El rostro y el carácter. Madrid: Ediciones Istmo.

Butler, H. E. 1979. Quintilian: The Institutio Oratoria of Quintilian. Vol. IV. Loeb Classical Library. London: Harvard University Press.

Cairus, H. F. e Ribeiro Jr. W. A. 2005. Textos Hipocráticos - O doente, o médico e a doença. Rio de Janeiro: FIOCRUZ.

Evans, E. C. 1969. Physiognomics in the Ancient World. Transactions of the American Philosophical Society, New Series, 59(5):1-101. 
Foerster, R. 1994. Scriptores Physiognomici Graeci et Latini. Vol.II [1893 - $1^{\text {a }}$ edição]. Leipzig: Teubner.

Lalande, A. 1999. Vocabulário técnico e crítico da filosofia. São Paulo: Martins Fontes.

Lamb, W. R. M. 1925. Plato: Lysis. Symposium. Gorgias. Loeb Classical Library. London: Harvard University Press.

Liddell, H. G. and Scott, R. 1996. A Greek-English Lexicon. Oxford: Clarendon Press. Edição revisada, $9^{a}$ edição.

Parry, R. 2007. "Episteme and Techne." In The Stanford Encyclopedia of Philosophy, edited by Edward N. Zalta), URL: <http://plato.stanford.edu/archives/fall2008/ entries/episteme-techne/>.

Pereira, João F. 2006. Xenofonte : Ciropedia - A educação de Ciro. Rio de Janeiro : Clássicos Jackson, 1956 - Versão para eBook : eBooksBrasil.

Pinheiro, A. E. 2011. Xenofonte : Memoráveis. São Paulo: Annablume.

Rodolpho, M. 2012. Écfrase e Evidência nas letras latinas: Doutrina e práxis. São Paulo: Humanitas.

Saraiva, F. R. dos S. 2000. Novíssimo Dicionário Latino-Português. Rio de Janeiro: Livraria Garnier, $11^{a}$ edição.

Sprague, R. K. 1973. Plato: Laches and Charmides. Loeb Classical Library. London: Harvard University Press.

Swain, S., ed. 2007. Seeing the face, seeing the soul. Polemonn's Physiognomy from Classical Antiquity to Medieval Islam. Oxford: Oxford University Press.

Title. Panthea: a verbal image.

Abstract. In this paper, we analyse the ekphrasis of character, since this kind is applied in physiognomical texts. It is necessary to understand the concept of physiognomony and how its theory contributes to the composition of portraits through the analysis of Philostratus' ekphrasis II, 9, in Eikones; in this text, he depicts Panthea's appearance through her known ethos. The treatise used to analyse the Panthea's portrait here is De Physiognomonia Liber (IV d.C.), of unknown author.

Keywords. Ekphrasis; enargeia; physiognomony; portrait; ethos. 